\title{
The Effect of Inhibition of Prostaglandin Synthesis on Urinary Sodium Excretion in the Conscious Dog
}

\author{
Michael A. Kirschenbaum and Jay H. Stein \\ From the Department of Medicine, The University of Texas Health Science \\ Center at San Antonio, San Antonio, Texas 78284
}

\begin{abstract}
A в S T R A C T Studies were performed to determine the effect of decreased endogenous release of renal prostaglandins on urinary sodium excretion. Two structurally dissimilar inhibitors of prostaglandin synthesis were employed, and studies were performed in conscious dogs allowed to recover from prior surgical instrumentation. Either meclofenamate $(2 \mathrm{mg} / \mathrm{kg})$ or the competitive prostaglandin inhibitor RO 20-5720 (1 $\mathrm{mg} / \mathrm{kg}$ ) was given to seven unanesthetized dogs undergoing a water diuresis. The administration of either prostaglandin inhibitor did not alter glomerular filtration rate, renal plasma flow, urinary volume, or potassium excretion. Sodium excretion, however, increased from 32 to $130 \mu \mathrm{eq} / \mathrm{min}(P<0.02)$. Essentially, the entire increase in sodium excretion was due to an increase in urinary sodium concentration from 7.7 to 28.3 $\mathrm{meq} / \mathrm{liter}(P<0.02)$. On a different day, the same animals were studied before and after administration of the diluent of the prostaglandin inhibitor. No change was noted in sodium excretion or any other parameter.

Thus, these findings suggest that prostaglandin inhibition in the conscious dog is associated with a natriuresis without a change in urinary volume or potassium excretion during water diuresis. This may indicate that the natriuresis was due to diminished sodium reabsorption beyond the distal tubule.
\end{abstract}

Received for publication 14 May 1975 and in revised form 10 October 1975.

\section{INTRODUCTION}

Prostaglandins of either the $A(P G A)^{1}$ or $E$ (PGE) series, when infused into the renal artery, cause an increase in urinary sodium excretion $(1,2)$. Therefore, it has been suggested that the endogenous release of these lipids might be a potent natriuretic stimulus and serve an important role in the regulation of sodium balance (1).

Yet, several recent findings concerning the synthesis and metabolism of prostaglandins must be considered. First, it is clear that $\mathrm{PGE}^{2}$ is the primary prostaglandin synthesized in the kidney while little or no synthesis of PGA has been noted $(3,4)$. Since PGE is almost completely inactivated in each passage across the lung (5), any action of this lipid on the kidney must be as a local tissue hormone and related to the renal synthesis of the prostaglandin. Second, although PGA does escape degradation in the lung (6), evidence is accumulating to indicate that PGA is not synthetized in the kidney (4), that it originates from the dehydration of $\mathrm{PGE}$, and

\footnotetext{
${ }^{1}$ Abbreviations used in this paper: FF, filtration fraction; GFR, glomerular filtration rate; PGA, prostaglandin A; PGE, prostaglandin E; PI, prostaglandin inhibition; RBF, renal blood flow; $R P F$, renal plasma flow; $U_{K} V$, urinary potassium excretion; $U_{\mathrm{Na}} \mathrm{V}$, urinary sodium excretion; $\mathrm{V}$, urinary volume.

${ }^{2}$ In this paper, no distinction is made between $\mathrm{PGE}_{1}$ and $\mathrm{PGE}_{2}$ although it is recognized that $\mathrm{PGE}_{2}$ is the primary renal prostaglandin (3).
} 
that its concentration in peripheral blood, at least in man, is very low (7). Third, PGE is primarily synthesized in the renal medulla (8). Thus, the intrarenal infusion of PGE would not necessarily mimic its physiological action, since it is synthesized in the medulla and may have its primary action in this area of the kidney.

With these points in mind, it would seem that an evaluation of the physiological role of prostaglandins on urinary sodium excretion would necessitate an experimental design, in which the endogenous production of the lipids was altered. Recent studies have clearly defined a number of agents which inhibit the synthesis of renal prostaglandins $(9,10)$. Thus, these various antiinflammatory agents could be utilized to inhibit the in vivo production of renal prostaglandins and determine what effect this may have on urinary sodium excretion.

It has been shown that prostaglandin inhibition (PI) in the anesthetized dog causes a marked increase in renal resistance (11). Thus, in the anesthetized dog, any nonhemodynamic effect of PI on sodium excretion would be difficult to discern. Zins (12), however, has reported that the administration of a prostaglandin inhibitor to an unanesthetized dog was not associated with a fall in renal blood flow ( $R B F)$. Therefore, it was the purpose of this study to investigate the effect of PI on sodium excretion in a group of conscious dogs. The results of these studies suggest that $\mathrm{PI}$ is natriuretic in this setting.

\section{METHODS}

Studies were performed on mongrel dogs of both sexes weighing between 15 and $24 \mathrm{~kg}$. The animals were anesthetized and endotracheal intubation was performed. A Goodale-Lubin standard wall catheter was threaded into the left ventricle through the right carotid artery for the injection of radioactive microspheres. The left brachial artery was catheterized for the withdrawal of a reference sample for RBF determination. A catheter was placed in the right jugular vein for the administration of intravenous fluids and drugs. After surgery, the animals were allowed to recover for several days before they were studied. Before study, a Foley catheter was passed into the bladder for urine collection. An infusion of $5 \%$ dextrose in water was begun at a rate of $25 \mathrm{ml} / \mathrm{kg}$ administered over $30 \mathrm{~min}$, and then a maintenance infusion of $1-2 \mathrm{ml} / \mathrm{min}$ greater than urine flow was continued for the entire duration of the study. After $30 \mathrm{~min}$ of maintenance infusion, three control clearance periods and injection of the first microsphere was performed. Then in four of the seven studies, either meclofenamate $(2 \mathrm{mg} / \mathrm{kg})$ or RO $20-5720(1 \mathrm{mg} / \mathrm{kg})$, both prostaglandin inhibitors (vide infra), were administered intravenously, and after $45 \mathrm{~min}$, three clearance periods and a repeat microsphere injection were obtained. The animals were allowed to recover for 2 days. Then the protocol was repeated, except that the diluent of the prostaglandin inhibitor was administered rather than the inhibitor itself before the second period of study. The sequence of the protocol was reversed in the remaining three animals by giving the diluent in the first study and the prostaglandin inhibitor in the second study. The two phases of each individual study were performed at the same time of day in each animal.

Meclofenamate (Parke, Davis \& Co., Detroit, Mich.) was dissolved in saline. RO 20-5720 (Hoffmann-La Roche, Inc., Nutley, N. J.), a competitive inhibitor of prostaglandin synthesis, was prepared in bicarbonate solution. Unlike either indomethacin or meclofenamate, RO $20-5720$ is a very poor inhibitor of phosphodiesterase. ${ }^{3}$ RO 20-5720 $(1 \mathrm{mg} / \mathrm{kg}$ ), when administered intravenously into dogs ( $n$ $=4)$, lowered renal venous PGE levels from $358 \pm 12$ to $180 \pm 12 \mathrm{pg} / \mathrm{ml}(P<0.005)$ as measured by radioimmunoassay techniques previously described (13).

Radioactive microspheres $15 \pm 5 \mu \mathrm{m}$ in diameter (3M Co., St. Paul, Minn.) were used to measure total RBF. The nuclides utilized were ${ }^{85} \mathrm{Sr}$, and ${ }^{141} \mathrm{Ce}$. The sequence of injection was alternated. Total RBF was measured using a modified indicator dilution technique with the microspheres as previously described and validated from this and other laboratories $(11,14,15)$.

Glomerular filtration rate (GFR) was estimated from the clearance of inulin. Clearances were determined in each experimental period for three 10-min periods, with an arterial blood sample collected at the midpoint of each period. Plasma and urine inulin concentrations were determined by the anthrone method (16). Plasma and urinary sodium concentrations were determined with a flame photometer (Instrumentation Laboratory, Inc., Lexington, Mass.). Urinary osmolality was determined with an osmometer (Advanced Instruments, Inc., Needham Heights, Mass.).

Calculations. (a) The calculation of RBF using radioactive microspheres has previously been described $(11,15)$. (b) Renal plasma flow (RPF) was calculated by the formula : $\mathrm{RPF}=\mathrm{RBF} \times(1-$ hematocrit $)$. (c) Filtration fraction (FF) was calculated by the formula: $F F=G F R$ / RPF. Statistical analysis was performed by standard methods and the data are presented as the mean \pm SEM.

\section{RESULTS}

The results of the studies are shown in Table I. The clearance data represent two kidney values and are the mean of three collection periods. The mean urinary osmolality at the beginning of each study was 87 mos$\mathrm{mol} / \mathrm{kg}$ and ranged from 63 to $118 \mathrm{mosmol} / \mathrm{kg}$. Urine volume did not change after $\mathrm{PI} ; 3.8 \pm 0.4$ compared to $4.4 \pm 0.5 \mathrm{ml} / \mathrm{min}$. GFR $(55 \pm 4.0$ vs. $55 \pm 4.4)$, RPF $(180 \pm 9.1$ vs. $179 \pm 7.8)$, and filtration fraction $(0.30 \pm 0.02$ vs. $0.31 \pm 0.02)$ were also not changed after PI. Urinary sodium excretion $\left(\mathrm{U}_{\mathrm{Na}} \mathrm{V}\right)$, however, increased in each study from $32.1 \pm 11.7$ to $130.0 \pm 32.2$ $\mu \mathrm{eq} / \mathrm{min}(P<0.02)$. This increase in $\mathrm{U}_{\mathrm{Na}} \mathrm{V}$ was almost totally due to a rise in urinary sodium concentration from $7.7 \pm 2.3$ to $28.3 \pm 5.0 \mathrm{meq} /$ liter $(P<0.02)$. The fractional excretion of sodium increased from $0.46 \pm$ 0.16 to $1.69 \pm 0.35 \%(P<0.01)$. There was no change in potassium excretion, $24.1 \pm 9.2$ during the control period, compared to $23.0 \pm 9.4 \mu \mathrm{eq} / \mathrm{min}$ after PI. In studies in which the diluent of the inhibitor was given rather than the agent itself, no change in urinary vol-

\footnotetext{
${ }^{3}$ Paulsrud, J. R., Hoffmann-La Roche, Inc., Nutley, N. J. Personal communication.
} 
TABLE I

Effect of Prostaglandin Inhibition in Conscious Dogs

\begin{tabular}{|c|c|c|c|c|c|c|c|c|c|c|c|c|c|c|c|c|c|c|c|c|c|c|}
\hline \multirow{2}{*}{$\begin{array}{c}\text { Exp. } \\
\text { no. }\end{array}$} & \multicolumn{2}{|c|}{$\mathrm{V}$ rate } & \multicolumn{2}{|c|}{ GFR } & \multicolumn{2}{|c|}{ RPF } & \multicolumn{2}{|c|}{ FF } & \multicolumn{2}{|c|}{$\mathrm{U}_{\mathrm{Na}}$} & \multicolumn{2}{|c|}{$\mathrm{UNaV}_{\mathrm{Na}}$} & \multicolumn{2}{|c|}{$\mathrm{FE}_{\mathrm{Na}}$} & \multicolumn{2}{|c|}{$\mathrm{UK}_{\mathbf{K}}$} & \multicolumn{2}{|c|}{$\mathrm{UKV}_{\mathbf{K}}$} & \multicolumn{2}{|c|}{$\mathrm{FE}_{\mathbf{K}}$} & \multicolumn{2}{|c|}{ BP } \\
\hline & C & $\mathrm{E}$ & C & $\mathbf{E}$ & C & $\mathbf{E}$ & $\mathbf{C}$ & $\mathbf{E}$ & C & $\mathbf{E}$ & C & $\mathbf{E}$ & C & $\mathbf{E}$ & C & $\mathbf{E}$ & C & $\mathbf{E}$ & C & $\mathbf{E}$ & C & $\mathbf{E}$ \\
\hline & \multicolumn{2}{|c|}{$\operatorname{ml} / \min$} & \multicolumn{2}{|c|}{$\operatorname{ml} / \min$} & \multicolumn{2}{|c|}{$\operatorname{ml} / \min$} & & & \multicolumn{2}{|c|}{ meq/liter } & \multicolumn{2}{|c|}{$\mu e q / \min$} & \multicolumn{2}{|c|}{$\%$} & \multicolumn{2}{|c|}{ meq/liter } & \multicolumn{2}{|c|}{$\mu e q / \min$} & \multicolumn{2}{|c|}{$\%$} & \multicolumn{2}{|c|}{$m m H g$} \\
\hline \multicolumn{23}{|c|}{ Prostaglandin inhibition studies } \\
\hline $1(\mathrm{M})$ & $2.8^{*}$ & 4.2 & 59 & 72 & 198 & 182 & 0.30 & 0.40 & 2.5 & 8.5 & 7.0 & 36.2 & 0.08 & 0.36 & 10.3 & 2.8 & 28.8 & 11.4 & 12.2 & 4.0 & 104 & 105 \\
\hline $2(M)$ & 5.4 & 7.3 & 60 & 63 & 224 & 220 & 0.26 & 0.29 & 16.2 & 39.3 & 87.4 & 287.4 & 1.04 & 3.26 & 14.3 & 10.7 & 76.6 & 78.1 & 31.9 & 30.9 & 120 & 120 \\
\hline $3(\mathrm{M})$ & 4.3 & 4.7 & 68 & 54 & 166 & 168 & 0.40 & 0.32 & 0.4 & 37.8 & 1.9 & 177.0 & 0.02 & 2.34 & 3.6 & 1.3 & 15.1 & 5.9 & 5.6 & 2.7 & 90 & 90 \\
\hline $4(R)$ & 3.1 & 3.4 & 62 & 63 & 162 & 170 & 0.39 & 0.36 & 3.1 & 46.6 & 10.2 & 158.4 & 0.12 & 1.80 & 6.3 & 6.0 & 21.4 & 20.3 & 8.6 & 8.1 & 90 & 90 \\
\hline $5(R)$ & 3.0 & 3.2 & 52 & 52 & 182 & 184 & 0.28 & 0.28 & 7.8 & 22.6 & 23.6 & 73.2 & 0.32 & 1.01 & 4.2 & 2.2 & 12.7 & 8.7 & 6.1 & 4.2 & 75 & 75 \\
\hline $6(\mathrm{R})$ & 4.1 & 4.5 & 41 & 42 & 168 & 160 & 0.24 & 0.27 & 9.8 & 22.4 & 39.8 & 100.8 & 0.69 & 1.71 & 1.4 & 4.4 & 5.7 & 19.7 & 3.5 & 11.7 & 83 & 80 \\
\hline $7(M)$ & 3.6 & 3.5 & 41 & 40 & 157 & 163 & 0.26 & 0.25 & 14.4 & 21.0 & 54.6 & 76.9 & 0.95 & 1.37 & 2.2 & 4.6 & 8.3 & 16.9 & 5.1 & 10.6 & 78 & 75 \\
\hline Mean & 3.8 & 4.4 & 55 & 55 & 180 & 179 & 0.30 & 0.31 & 7.7 & 28.3 & 32.1 & 130.0 & 0.46 & 1.69 & 6.0 & 4.6 & 24.1 & 23.0 & 10.4 & 10.3 & 91 & 91 \\
\hline SEM & 0.4 & 0.5 & 4.0 & 4.4 & 9.1 & 7.8 & 0.02 & 0.2 & 2.3 & 5.0 & 11.7 & 32.2 & 0.16 & 0.35 & 1.8 & 1.2 & 9.2 & 9.4 & 3.7 & 3.7 & 5.9 & 6.3 \\
\hline $\boldsymbol{P}$ & \multicolumn{2}{|c|}{ NS } & \multicolumn{2}{|c|}{ NS } & $\mathbf{N}$ & $\mathbf{S}$ & $\mathrm{N}$ & & $<0$ & .02 & $<0$ & .02 & $<0$ & 0.01 & $\mathbf{N}$ & & $\mathrm{N}$ & is & $\mathbf{N}$ & JS & $\mathbf{N}$ & S \\
\hline Diluent ir & jectio & on stu & lies & & & & & & & & & & & & & & & & & & & \\
\hline 1 & 3.3 & 3.3 & 63 & 79 & & & & & 1.4 & 2.0 & 4.5 & 6.5 & 0.05 & 0.06 & 5.9 & 4.4 & 19.4 & 14.5 & 7.7 & 4.6 & 110 & 110 \\
\hline 2 & 5.0 & 5.9 & 62 & 61 & & & & & 20.2 & 18.1 & 101.6 & 106.0 & 1.17 & 1.24 & 5.7 & 12.4 & 79.2 & 72.9 & 31.9 & 29.9 & 115 & 115 \\
\hline 3 & 3.6 & 4.0 & 58 & 56 & & & & & 1.6 & 1.5 & 5.6 & 6.6 & 0.07 & 0.08 & 8.1 & 7.7 & 29.0 & 30.7 & 12.5 & 13.7 & 85 & 85 \\
\hline 4 & 3.0 & 3.0 & 59 & 61 & & & & & 3.4 & 2.7 & 10.0 & 8.0 & 0.12 & 0.09 & 5.2 & 5.1 & 15.6 & 15.1 & 6.6 & 6.2 & 93 & 93 \\
\hline 5 & 2.4 & 2.8 & 50 & 52 & & & & & 10.2 & 9.5 & 20.8 & 26.6 & 0.30 & 0.36 & 3.7 & 3.6 & 8.8 & 10.3 & 4.4 & 4.9 & 70 & 70 \\
\hline 6 & 3.6 & 4.0 & 40 & 40 & & & & & 10.2 & 9.6 & 36.7 & 33.6 & 0.65 & 0.60 & 2.4 & 2.7 & 8.4 & 9.6 & 5.3 & 6.0 & 80 & 80 \\
\hline 7 & 3.9 & 4.0 & 41 & 42 & & & & & 12.7 & 11.6 & 49.8 & 46.3 & 0.87 & 0.79 & 2.8 & 4.0 & 11.0 & 12.0 & 6.7 & 7.1 & 80 & 80 \\
\hline Mean & 3.5 & 3.8 & 53 & 56 & & & & & 8.5 & 7.9 & 32.7 & 33.4 & 0.46 & 0.46 & 6.3 & 5.7 & 24.5 & 23.6 & 10.7 & 10.3 & 90 & 90 \\
\hline SEM & 0.3 & 0.4 & 3.7 & 5.0 & & & & & 2.6 & 2.3 & 13.1 & 13.4 & 0.17 & 0.17 & 1.7 & 1.3 & 9.5 & 8.6 & 3.7 & 3.4 & 6.3 & 6.3 \\
\hline$P$ & N & & $\mathbf{N}$ & & & & & & $\mathbf{N}$ & & $\mathbf{N}$ & & $\mathbf{N}$ & & $\mathrm{N}$ & & N & & $\mathbf{N}$ & & $N$ & \\
\hline
\end{tabular}

Abbreviations: C, Control period; E, Experimental period; $M$, meclofenamate; R, RO 20-5720; UNa, urinary sodium concentration; FE $\mathrm{Na}_{\mathrm{a}}$ fractional sodium excretion; $U_{K}$, urinary potassium concentration; $F_{K}$, fractional potassium excretion; $B P$, blood pressure.

* All values presented are for the sum of both kidneys.

ume, GFR, $U_{\mathrm{Na}} \mathrm{V}$, or urinary potassium excretion $\left(\mathrm{URV}_{\mathrm{K}}\right.$ ) was noted. Blood pressure was constant in each period during both protocols.

\section{DISCUSSION}

In this study, the effect of the administration of prostaglandin inhibitors on $\mathrm{U}_{\mathrm{Na}} \mathrm{V}$ was evaluated. Two dissimilar inhibitors of prostaglandin synthesis were used to decrease endogenous renal prostaglandin release. We and others have shown that the intravenous administration of meclofenamate in the dose used in this study is associated with a significant decrease in renal prostaglandin release, which lasts for well over $2 \mathrm{~h}(13,17)$. The structurally and functionally dissimilar compound, RO 20-5720, which has been shown to compete with arachidonic acid for prostaglandin synthetase activity, has similarly been demonstrated to inhibit prostaglandin release (vide supra). Administration of these agents in the anesthetized dog, however, has been associated with a marked fall in RBF (11). Thus, it would be difficult to determine whether inhibition of prostaglandin synthesis could alter sodium excretion by nonhemodynamic means. Since Zins (12) has shown that RBF was not changed in conscious dogs that were given comparable doses of prostaglandin inhibitors, our studies were per- formed to determine whether any change in sodium excretion could be discerned in this setting. The basis for the difference in renal hemodynamic alterations in the conscious dog in comparison with the anesthetized dog is not clear but may relate to the greater sympathetic tone and renin release seen during anesthesia (18). PI may alter renal resistance only when these vasoconstrictor stimuli are augmented. In any case, the data in Table I confirm the results of Zins by demonstrating no change in RPF after PI in the conscious dog. In addition, there was no change in GFR, urine volume, $\mathrm{U}_{\mathbf{K}} \mathrm{V}$, or mean arterial pressure after administration of the prostaglandin inhibitors. The only change noted was a fourfold increase in $U_{\mathrm{Na}} \mathrm{V}$, which was due almost totally to an increase in urinary sodium concentration. No change in any parameter was noted in the diluent injection studies.

These results suggest that the administration of meclofenamate or RO $20-5720$ has some direct tubular action on sodium transport. One interpretation of these results would be that this effect was mediated by the individual drugs by a mechanism independent of inhibition of prostaglandin synthesis. Yet, these agents differ markedly in chemical structure and in their mechanism of inhibition of prostaglandin synthesis. RO 20-5720 
competes with arachidonic acid for prostaglandin synthetase activity. ${ }^{3}$ As a competitive inhibitor of prostaglandin synthesis, the addition of excess arachidonic acid after administration of RO 20-5720 functionally restores PGE production. ${ }^{3}$ Although not as well delineated, meclofenamate appears to be an irreversible inhibitor of prostaglandin synthesis which interferes with the formation of prostaglandins by its effect on the enzyme, prostaglandin synthetase (10). Thus, it is difficult to hypothesize that both of these agents have a direct tubular effect on sodium transport; rather it seems more likely that the alterations noted are due to their one common action, the inhibition of prostaglandin synthesis. Thus, these data would suggest that inhibition of prostaglandin synthesis under certain circumstances is natriuretic.

These results may seem surprising because the intrarenal infusion of $\mathrm{PGE}$ or $\mathrm{PGA}$ results in a natriuresis $(1,2)$. Yet, the infusion of either of these agents causes hemodynamic alterations (i.e. the rise in RBF and fall in FF) similar to those seen with other renal vasodilators which also cause a natriuresis. In addition, the recent data which demonstrates that PGE is inactivated after passage through the lungs $(5,7)$, and that PGA is, in all likelihood, a degradation product of PGE (4), makes the physiological significance of studies that evaluate the intrarenal infusion of either of these lipids tenuous. These studies only seem to indicate that there is a vascular receptor which is affected by the intrarenal infusion of either PGE or PGA leading to renal vasodilatation. In all likelihood, the natriuresis seen with the intrarenal infusion of PGE and PGA is due to the same hemodynamic alterations caused by bradykinin, acetylcholine, and other vasodilators $(19,20)$.

Tannenbaum et al. (21) have recently found that the intrarenal infusion of sodium arachidonate caused a 43$\mu \mathrm{eq} / \mathrm{min}$ increase in sodium excretion and a rise in renal venous $P G E$ as determined by bioassay. Although this would seem to be contradictory to the findings in the present study, certain points should be evaluated. Arachidonic acid is unstable in vitro. Storage at $-20^{\circ} \mathrm{C}$, daily preparation, handling and storage under nitrogen atmosphere, and the addition of chemical agents have been used by various laboratories to prevent the autooxidation of arachidonic acid to substances in the prostaglandin series (22). Thus, the formation of prostaglandin endoperoxides might occur during the intrarenal infusion of arachidonic acid. Even while taking this aspect into consideration, recent studies from this laboratory have demonstrated that the infusion of sodium arachidonate during prostaglandin inhibition with $\mathrm{RO}$ 20-5720 returns $\mathrm{RBF}$ to normal without a change in $\mathrm{U}_{\mathrm{Na}} \mathrm{V}$ (23). These results are quite different from the natriuresis seen during prostaglandin inhibition when other vasodilators are utilized to restore $\mathrm{RBF}$, but not prostaglandin synthesis (23). Thus, the restoration of $\mathrm{RBF}$ in association with increased endogenous prostaglandin release in prostaglandin inhibited dogs does not result in a natriuresis.

Therefore, we interpret our studies to indicate that inhibition of prostaglandin synthesis may lead to a natriuresis. This is compatible with the data of Lipson and Sharp (24), who found that the application of PGE to the serosal side of the toad bladder increased short circuit current and sodium transport. These findings are of major interest, because of the view that the renal action of PGE is primarily at the local site of production in the renal medulla (25). In this regard, the data in Table I suggest that the natriuretic action of prostaglandin inhibition is most likely beyond the distal tubule since urinary volume and potassium excretion were not increased, while urinary sodium concentration rose fourfold. This would suggest that the delivery of sodium to the diluting segment and to the distal potassium secretory site was unaltered. It is tempting to suggest that collecting-duct sodium transport is diminished when the local release of PGE is decreased.

\section{ACKNOWLEDGMENTS}

This work was supported, in part, by National Institutes of Health research grants AM 17387-02 and AM 18485-01, and by a grant from the American Heart Association.

\section{REFERENCES}

1. Lee, J. B. 1973. Hypertension, natriuresis, and the renomedullary prostaglandins: an overview. Prostaglandins. 3: 551-579.

2. Vander, A. J. 1968. Direct effects of prostaglandins on renal function and renin release in the anesthetized dog. Am. J. Physiol. $214:$ 218-221.

3. Daniels, E. G., J. W. Hinman, B. E. Leach, and E. E. Muirhead. 1967. Identification of prostaglandin $\mathrm{E}_{\mathrm{z}}$ as the principle vasodepressor lipid of rabbit renal medulla. Nature (Lond.). 215: 1298-1299.

4. Crowshaw, K. 1973. The incorporation of $\left[1{ }^{14} \mathrm{C}\right]$ arachidonic acid into the lipids of rabbit renal slices and conversion to prostaglandin $\mathrm{E}_{2}$ and $\mathrm{F}_{2} \alpha$. Prostaglandins. 3 : $607-620$.

5. Ferreira, S. H., and J. R. Vane. 1967. Prostaglandins: their disappearance from and release into the circulation. Nature (Lond.). 216: 868-873.

6. McGiff, J. C., N. A. Terragno, J. C. Strand, J. B. Lee, A. J. Lonigro, and K. K. K. F. Ng. 1969. Selective passage of prostaglandins across the lung. Nature (Lond.). 223 : 742-745.

7. Frolich, J. C., B. J. Sweetman, K. Carr, J. T. Watson, and $J$. Oates. 1975. Measurement of prostaglandin $A_{2}$ (PGA ) plasma levels by gas chromatography-mass spectrometry (GC/MS). Clin. Res. 23: 35A. (Abstr.)

8. Crowshaw, K. 1971. Prostaglandin biosynthesis from endogenous precursors in rabbit kidney. Nat. New Biol. 231: 240-242. 
9. Vane, J. R. 1971. Inhibition of prostaglandin synthesis as a mechanism of action of aspirin-like drugs. Nat. New Biol. 231 : 232-235.

10. Flower, R. J. 1974. Drugs which inhibit prostaglandin biosynthesis. Pharmacol. Rev. 26: 33-67.

11. Kirschenbaum, M. A., N. White, J. H. Stein, and T. F. Ferris. 1974. Redistribution of renal cortical blood flow during inhibition of prostaglandin synthesis. $\mathrm{Am}$. J. Physiol. 227: 801-805.

12. Zins, G. R. 1975. Renal prostaglandins. Am. J. Med. 58: 14-24.

13. Venuto, R. C., T. O'Dorisio, T. F. Ferris, and J. H. Stein. 1975. Prostaglandins and renal function. II. The effect of prostaglandin inhibition on autoregulation of blood flow in the intact kidney of the dog. Prostaglandins. 9: 817-828.

14. Arruda, J. A. L., S. Boonjarern, C. Westenfelder, and N. A. Kurtzman. 1974. Measurement of renal blood flow with radioactive microspheres. Proc. Soc. Exp. Biol. Med. 146: 263-264.

15. Cox, J. W., R. W. Baehler, H. Sharma, T. O'Dorisio, R. W. Osgood, J. H. Stein, and T. F. Ferris. 1974. Studies on the mechanism of oliguria in a model of unilateral acute renal failure. J. Clin. Invest. 53: 1546-1558.

16. Fuhr, J., J. Kaczmarczyk, and C-D. Kruttgen. 1955. Eine einfache Kolorometrische Methode zur Inulin Bestimmung fur Nierenclearanceuntersuchungen bei Stoffwechselgesunden und Diabetikern. Klin. Wochen schr. 33: 729-730.

17. Lonigro, A. J., H. D. Itskovitz. K. Crowshaw, and J. C. McGiff. 1973. Dependency of renal blood flow on prostaglandin synthesis in the dog. Circ. Res. 32: 712717.

18. Pettinger, W. A., M. Marchelle, and L. Augusto. 1971. Renin suppression by $\mathrm{DOC}$ and $\mathrm{NaCl}$ in the rat. Am. J. Physiol. 221: 1071-1074.

19. Earley, L. E., and R. M. Friedler. 1966. The effects of combined renal vasodilatation and pressor agents on renal hemodynamics and the tubular reabsorption of sodium. J. Clin. Invest. 45: 542-551.

20. Stein, J. H., T. F. Ferris, J. E. Huprich, T. C. Smith, and R. W. Osgood. 1971. Effect of renal vasodilatation on the distribution of cortical blood flow in the kidney of the dog. J. Clin. Invest. 50: 1429-1438.

21. Tannenbaum, J., J. A. Splawinski, J. A. Oates, and A. S. Nies. 1975. Enhanced renal prostaglandin production in the dog: I. Effect on renal function. Circ. Res. 36: 197-203.

22. Splawinski, J. A., A. S. Nies, B. Sweetman, and J. A. Oates. 1973. Effect of arachidonic acid, prostaglandin $E_{2}$ and prostaglandin $F_{2} \alpha$ on the longitudinal stomach strip of the rat. J. Pharmacol. Exp. Ther. 187: 501-510.

23. Kirschenbaum, M. A., W. H. Bay, T. F. Ferris, and J. H. Stein. 1975. The effect of prostaglandin inhibition (PI) on the natriuresis of drug induced renal vasodilatation. Clin. Res. 23: 36A. (Abstr.)

24. Lipson, L. C., and G. W. G. Sharp. 1971. Effect of prostaglandin $E_{1}$ on sodium transport and osmotic water flow in the toad bladder. Am. J. Physiol. 220: 10461052.

25. McGiff, J. C., and H. D. Itskovitz. 1973. Prostaglandins and the kidney. Circ. Res. 33: 479-488. 